\title{
Analisa Dan Perbandingan Performa Hypervisor ESXi, XEN, VMWARE Workstation Pro, Dan VirtualBox
}

\author{
Totok Wahyu Caturiyanto ${ }^{1)}$, Arief Setyanto ${ }^{2)}$, Eko Pramono ${ }^{3)}$ \\ ${ }^{123}$ Magister Teknik Informatika Universitas Amikom Yogyakarta \\ ${ }^{123}$ Jl Ringroad Utara, Condongcatur, Depok, Sleman, Yogyakarta \\ 1'totokwahyu77@gmail.com, ${ }^{2}$ arief_s@amikom.ac.id, ${ }^{3}$ eko.p@amikom.ac.id
}

\begin{abstract}
Abstrak
Virtualisasi memberi kita banyak ruang untuk berkembang dalam teknologi informasi, dengan satu unit server kita dapat membuat mesin virtual sebanyak yang kita butuhkan. Mengurangi biaya investasi dan operasional untuk memajukan sisi lain bisnis adalah salah satu keuntungan virtualisasi. Salah satu perangkat lunak untuk menjembatani mesin virtual adalah hypervisor atau monitor mesin virtual. Tujuan dari penulisan ini adalah untuk mengetahui hypervisor mana yang merupakan performa terbaik dari keempat hypervisor yang dipilih oleh penulis yang mewakili setiap jenis hypervisor. ESXi, Xen, VMWare Workstation Pro dan Virtualbox. ESXi mewakili hypervisor baremetal berlisensi berbayar, Xen mewakili hypervisor baremetal versi gratis, VMWare Workstation Pro mewakili hosted hypervisor versi berlisensi dan Virtualbox mewakili hosted hypervisor versi gratis. Percobaan dilakukan dengan satu mesin, dengan sumber daya yang sama, dilakukan secara mandiri dan bergantian. Makalah ini menggunakan metode eksperimental untuk mendeskripsikan proses. Kesimpulannya adalah bahwa versi berlisensi atau versi gratis dari empat hypervisor yang disebutkan di atas tidak memengaruhi kinerjanya, hanya berapa banyak fitur yang tersedia dari pengembang.
\end{abstract}

Kata kunci:Performa Hypervisor, Virtualisasi, Mesin Virtual, Cloud Computing

\section{PENDAHULUAN}

Belanja modal dan belanja operasional infrastruktur menjadi isu penting dalam sebuah perusahaan. Kebutuhan akan aplikasi yang semakin meningkat membuat divisi teknologi informasi membutuhkan banyak anggaran untuk pengadaan dan operasional server. Teknologi virtualisasi adalah solusi paling tepat untuk mengurangi besaran anggaran. Dengan virtualisasi kita dapat mengembangkan banyak aplikasi atau server dalam satu mesin dengan berbagi sumber daya pada mesin itu. Secara teknis virtualisasi diwujudkan dengan menambahkan satu bagian (lapisan) perangkat lunak (software) yang disebut dengan hypervisor (Mulyana, 2015).Banyak hypervisor yang berkembang saat ini, baik itu hypervisor logam kosong atau hypervisor yang dihosting, hypervisor gratis, atau hypervisor berlisensi. Penulis mengambil sampel dari masingmasing jenis tersebut. ESXi mewakili hypervisor berlisensi baremetal, Xen mewakili hypervisor bebas baremetal, VMware Workstation Pro mewakili hypervisor berlisensi yang di-host, dan
Virtualbox mewakili hypervisor yang dihosting gratis dengan menguji kinerja CPU, RAM, dan Harddisk. Performa jaringan tidak diikutsertakan dalam pengujian karena beberapa faktor eksternal yang mempengaruhinya, seperti bandwidth dan gangguan interferensi. Untuk mengurangi penyimpangan dari hasil pengujian, pengujian dilakukan lima belas kali run untuk setiap komponen pengujian.

\section{METODE PENELITIAN}

Metode yang digunakan dalam penelitian ini adalah metode eksperimental, untuk mencari hypervisor kinerja terbaik antara ESXi 6.7, server Xen, VMware Workstation Pro dan Virtualbox 6.1. Komponen pengujian adalah CPU, RAM dan Disk. Alat benchmarking kami menggunakan Phoronix Test Suite, untuk pengujian CPU kami memilih Cachebench dan Coremark.. Tes RAM dengan Ramspeed Floating Point, Stream dan Tinymembench. Uji media simpan dengan AIO-Stress dan Compilebench. 
Data diambil dalam lima belas kali pengulangan untuk setiap pengujian. Di atas hypervisor, instal server Ubuntu 16.04 sebagai sistem operasi tamu. Kami mengikuti ini dengan tes default untuk setiap alat (Cachebench, Coremark, Ramspeed, Stream, Tinymembench, AIO-Stress, dan Compilebench). Hypervisor dipasang secara bergantian dan hanya satu sistem operasi tamu untuk menjamin bahwa sumber daya dialokasikan hanya ke hypervisor yang diuji. Untuk hypervisor yang dihosting, kami menggunakan windows 10 pro sebagai host. Untuk memeriksa korelasi dan validitas hasil digunakan uji korelasi model korelasi product-moment Pearson dengan menghubungkan antara masing-masing nilai uji dengan nilai total yang diperoleh dari pengujian tersebut. Ada beberapa rumus yang dapat digunakan untuk menghitung Koefisien Korelasi Momen Produk Pearson atau " $r$ " Pearson, persamaan di bawah ini sebagai sampel

$$
r=\frac{n\left(\sum X Y\right)-\left(\sum X\right)\left(\sum Y\right)}{\sqrt{\left[n\left(\sum X^{2}\right)-\left(\sum X\right)^{2}\right]\left[n\left(\sum Y^{2}\right)-\left(\sum Y\right)^{2}\right]}}
$$

$\mathrm{r}=$ Pearson's correlation coefficient

$\mathrm{n}=$ number of paired scores

$\mathrm{X}=$ Score of the first variable

$\mathrm{Y}=$ score of the second variable

$\mathrm{XY}=$ the product of the two paired

scores

Or analogously:

$r=$

Covariance of variable $A$ and $B$

$\sqrt{(\text { variance deviation of variable } A) X(\text { variance of variablt }}$

Skor yang lebih besar kovarians semakin kuat hubungannya. Kovariansi tidak pernah bisa lebih besar dari produk deviasi standar dari dua variabel (Cramer, 1998) Pengumpulan data dilakukan secara berurutan mulai dari menginstal ESXi 6.7 sebagai hypervisor asli dan meletakkan server Ubuntu 16.04 di atasnya dengan sumber daya seperti yang kami sebutkan di atas. Kemudian kami menjalankan uji kinerja CPU. Setelah mengambil datanya, kita uji validitas datanya, jika datanya valid, lanjutkan ke RAM dan media simpan test performa dengan perlakuan yang sama seperti uji CPU. Setelah semua tes dan jelas dan lengkap, hapus ESXi 6.7 dengan menginstal server Xen pada mesin dan letakkan server Ubuntu 16.04 sama seperti
ESXi 6.7. Ambil data dari CPU, RAM dan uji media simpan dan periksa validitas data setelah mengambil dari komponen yang diuji, uji ulang jika data tidak valid. VMware workstation pro dan Virtualbox, hypervisor yang dihosting, pertama-tama kami menginstal Windows 10 pro sebagai host dengan semua sumber daya mesin, kemudian kami menginstal sumber daya VMware Workstation Pro 2 vCPU, RAM 6 GB, dan Penyimpanan 160 GB. Kemudian kami memasang Ubuntu Server 16.04 pada hypervisor VMware Workstation Pro. Setelah itu kita lakukan pengujian terhadap CPU, RAM dan Disk yang sama dengan hypervisor lainnya. Setelah semua pengujian selesai dan jelas, hapus VMware Workstation Pro untuk memastikan tidak ada sumber daya yang dialokasikan ke hypervisor lain. Di windows 10 sama dengan VMware Workstation Pro, instal Oracle Virtualbox dan lakukan semua hal yang sama dengan VMware Workstation Pro.

Untuk memvalidasi hasil tes, bandingkan skor korelasi Pearson dengan rtabel. R-tabel merupakan tabel yang biasa digunakan untuk menguji hasil uji validitas suatu instrumen penelitian kuantitatif. Tingkat signifikansi r-tabel yang kita gunakan adalah $5 \%$, artinya kita memiliki tingkat kesalahan $5 \%$. Dengan lima belas run of test yang berarti $\mathrm{N}=15$. Jika nilai korelasi Pearson $>$ r-tabel, item data valid. Namun jika skor korelasi pearson $<$ r-tabel maka item data tidak valid. Tabel 1 adalah r-tabel untuk tingkat signifikansi $5 \%$ dan $1 \%$.

Tabel 1. rTabel

\begin{tabular}{|c|c|c|}
\hline \multicolumn{3}{|c|}{ Distribusi nilai $\mathbf{r}_{\text {tabel }} \mathrm{S}$} \\
\hline \multirow{2}{*}{$\mathrm{N}$} & \multicolumn{2}{|c|}{ The Level of Significance } \\
\hline & $5 \%$ & $1 \%$ \\
\hline 3 & 0.997 & 0.999 \\
\hline 4 & 0.950 & 0.990 \\
\hline 5 & 0.878 & 0.959 \\
\hline 6 & 0.811 & 0.917 \\
\hline 7 & 0.754 & 0.874 \\
\hline 8 & 0.707 & 0.834 \\
\hline 9 & 0.666 & 0.798 \\
\hline 10 & 0.632 & 0.765 \\
\hline 11 & 0.602 & 0.735 \\
\hline 12 & 0.576 & 0.708 \\
\hline 13 & 0.553 & 0.684 \\
\hline 14 & 0.532 & 0.661 \\
\hline 15 & 0.514 & 0.641 \\
\hline 16 & 0.497 & 0.623 \\
\hline 17 & 0.482 & 0.606 \\
\hline 18 & 0.468 & 0.590 \\
\hline 19 & 0.456 & 0.575 \\
\hline 20 & 0.444 & 0.561 \\
\hline
\end{tabular}




\section{TINJAUAN PUSTAKA \\ a. Virtualisasi}

Pengertian virtualisasi menurut (Mulyana, 2015) adalah membuat versi virtual dari suatu sumber daya sehingga dalam satu sumber daya fisik dapat dijalankan atau disimpan beberapa sumber daya virtual sekaligus, asalkan kinerja setiap sumber daya virtual tidak berbeda secara signifikan dengan sumber daya fisik. sumber daya. Pengertian lain dari virtualisasi adalah teknologi yang memperkenalkan lapisan abstraksi antara perangkat lunak dan perangkat keras yang mendasarinya, yaitu platform fisik / host dan sistem operasi menggunakan perangkat lunak yang disebut monitor mesin virtual atau hypervisor (Finn \& Lownds, 2011). Membuat beberapa mesin virtual dalam satu mesin berarti berbagi resource dari mesin tersebut, oleh karena itu pembuatan mesin virtual harus terencana dan tepat. Dari Gambar 1 dapat dilihat dengan fisik server, RAM, dan penyimpanan input / output, kita dapat menempatkan hypervisor untuk menggantikan sistem operasi baik itu Linux maupun Windows. Kemudian di hypervisor kita dapat menginstal lebih dari satu sistem operasi dengan CPU, RAM dan Storage itu sendiri secara virtual.

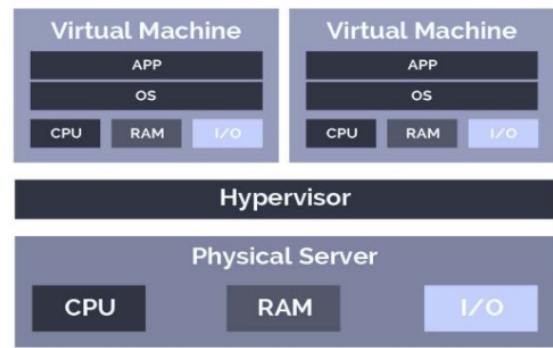

Gambar 1. Virtualisasi (Green et al., 2018)

\section{b. Virtual Machine Monitor}

Menurut (Finn \& Lownds, 2011) hypervisor adalah teknologi yang memperkenalkan lapisan abstraksi antara perangkat lunak, platform fisik / host dan sistem operasi yang merupakan mesin virtual, termasuk aplikasi yang berjalan di atasnya. Setiap mesin virtual atau sistem operasi akan dapat menjalankan programnya sendiri, seperti mesin virtual memiliki prosesor, memori, dan penyimpanannya sendiri. Namun pada kenyataannya, hypervisor yang mengalokasikan sumber daya tersebut ke mesin virtual. Dengan demikian, hypervisor memungkinkan untuk memiliki beberapa mesin virtual yang bekerja secara optimal pada satu perangkat keras komputer. Pengertian yang hampir seperti hypervisor adalah perangkat lunak yang memungkinkan beberapa server virtual berjalan pada satu perangkat keras (Green et al., 2018). Berdasarkan prinsip kerjanya, hypervisor dibedakan menjadi dua yaitu Native Hypervisor dan Hosted Hypervisor (Poojara et al., 2018). Native Hypervisor adalah hypervisor yang berjalan langsung pada perangkat keras untuk menangani mesin virtual. Sedangkan Hosted Hypervisor merupakan hypervisor yang berjalan pada sistem operasi konvensional baik varian Windows maupun Linux.

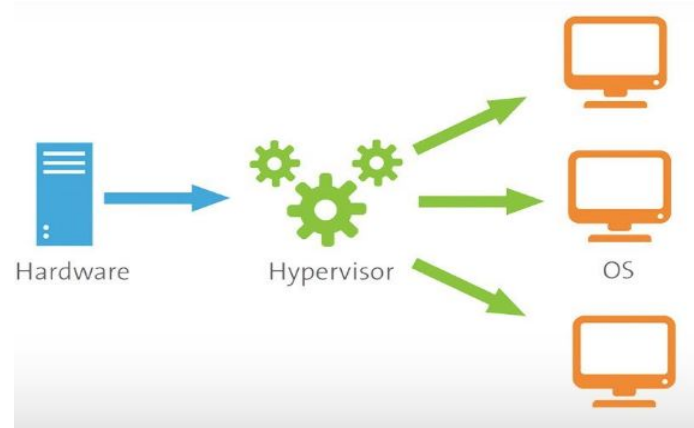

Gambar 2. Native Hypervisor

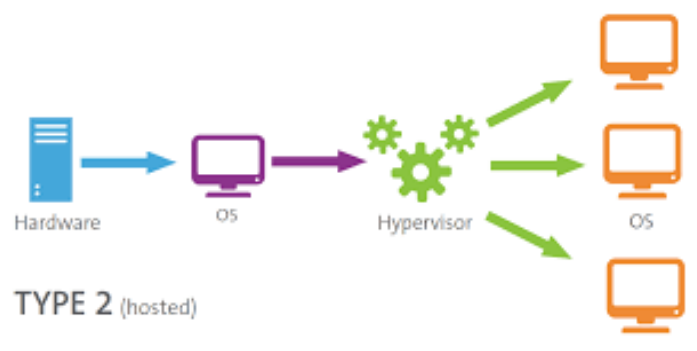

Gambar 3. Hosted Hypervisor

Menguji kinerja hypervisor HyperV, KVM, Xen dan ESXi (Hwang et al., 2014), (Karande \& Dhargave, 2015), (Manik \& ARORA, 2016) yang menguji kinerja CPU, media penyimpanan, RAM dan jaringan. Dengan berbagai alat pengujian yang berbeda, penelitian. Dengan berbagai alat pengujian yang berbeda, penelitian (Hwang et al., 2014), dengan menggunakan alat pengujian Bytemark, Ramspeed, Bonnie ++ \& FileBench dan netperf, sedangkan(Karande \& Dhargave, 2015) yang menggunakan Hadoop Benchmark, GPU Pass -through Performance, dan SIGAR Framework memiliki kesimpulan yang sama, walaupun hasil pengujiannya bervariasi, secara umum performa dari hypervisor VMware ESXi lebih baik dari hypervisor HyperV, KVM dan Xen. 
Sedangkan pada penelitian (Manik \& ARORA, 2016) dengan komponen pengujian yang sama yaitu penggunaan CPU, penggunaan RAM, kecepatan Disk dan kecepatan jaringan, disimpulkan bahwa setiap hypervisor memiliki kelebihannya masingmasing. Jika Anda membutuhkan komputasi intensif Anda dapat memilih Xen hypervisor, jika Anda membutuhkan lebih banyak memori intensif, Anda dapat memilih virtualisasi VMware. Kinerja hypervisor jika kondisi dan kebutuhan berbeda, maka kondisi tersebut dapat berbeda-beda

Penelitian (Poojara et al., 2018) dan (Graniszewski \& Arciszewski, 2016) (Fayyad et al., 2013) menganalisis dan membandingkan dua jenis hypervisor, hypervisor asli dan hypervisor yang dihosting. Perbedaan dalam penelitian (Poojara et al., 2018) tidak terdapat hypervisor yang memiliki performansi yang menonjol dari ketiga hypervisor yang digunakan untuk penelitian (Virtualbox 6.0, Vmware workstation 9.0 dan Xen). Meskipun pengujian hypervisor asli dan hypervisor yang dihosting menggunakan perangkat keras yang berbeda, untuk meminimalkan penyimpangan karena perangkat yang berbeda, perangkat keras yang sama ditentukan dan pengujian dilakukan hingga dua puluh lima kali. Sedangkan dalam penelitian (Graniszewski \& Arciszewski, 2016). Dengan menggunakan alat yang sama untuk menguji hypervisor asli dan hypervisor yang dihosting, kinerja ESXi, yang merupakan hypervisor asli, jauh lebih baik daripada yang lain. Penelitian Dalam penelitian (Fayyad et al., 2013) menyimpulkan bahwa hypervisor Xen lebih baik daripada hypervisor HyperV dan hypervisor Esxi, bahkan mendekati kinerja non-virtualisasi karena hypervisor Xen merupakan open source yang memungkinkan pengguna untuk mengontrol sepenuhnya seluruh sistem.

\section{HASIL DAN PEMBAHASAN \\ a. Kinerja CPU}

Gambar 4 di bawah ini menggambarkan kinerja CPU dari 4 hypervisor. Jumlah setiap tes yang diambil dari rata-rata lima belas tes berjalan. Ada dua bagian grafik batang, Cachebench Read dan Cachebench Write. Cachebench mewakili seberapa cepat prosesor membaca dan menulis memori cache, semakin tinggi skornya, semakin baik kinerjanya.. Untuk hypervisor Cachebench Xen sangat cukup baik daripada ESXi dan VMware Workstation Pro dan agak jauh dengan kinerja Virtualbox. Dalam uji Coremark, VMware Workstation Pro jauh lebih baik daripada yang lain dan dalam hal virtualbox adalah kinerja yang paling rendah.

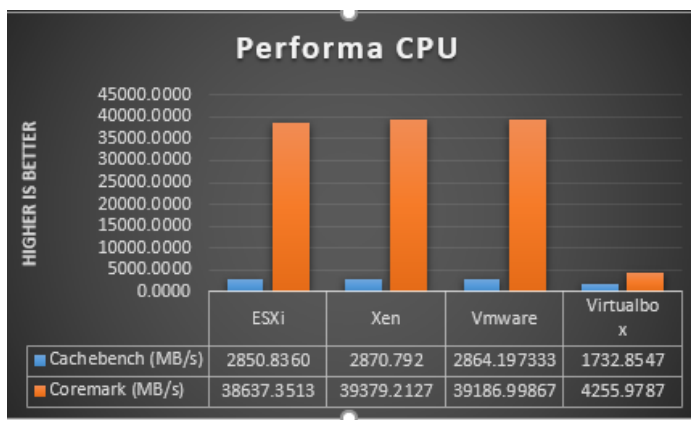

Gambar 4. Kinerja CPU

\section{c. Kinerja RAM}

Gambar 5 merepresentasikan performa RAM dengan tiga bagian grafik batang. Bar pertama adalah tes floating point kecepatan ram. Tes floating point adalah mengukur seberapa cepat memori memproses angka yang sangat besar atau sangat kecil. Semakin tinggi skor kinerja RAM yang lebih baik. Bagian kedua adalah pengujian Stream, yang mengukur bandwidth memori berkelanjutan (dalam MB / s) dan kecepatan komputasi yang sesuai untuk kernel vektor sederhana. Skor lebih tinggi, performa lebih baik untuk hasil tes Stream. Dan bilah bagian ketiga adalah tes Tinymembench yang mengukur bandwidth puncak dari akses memori sekuensial dan latensi RAM. Ini juga sama dengan tes RAM lainnya, skor lebih tinggi, kinerja lebih baik. Secara umum, untuk kinerja RAM, Xen Server hypervisor lebih baik daripada tiga hypervisor lainnya dan untuk ESXi, VMware Workstation Pro, Virtualbox memiliki perbedaan kinerja yang sangat kecil di antara mereka.

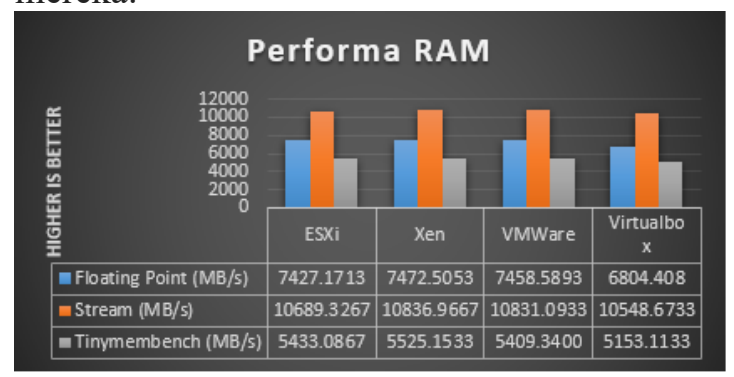

Gambar 5. Kinerja RAM 


\section{d. Kinerja Storage}

Gambar 6 mengilustrasikan kinerja storage untuk dua pengujian. Bagian bar pertama adalah AIO-Stress test yang menguji operasi input output asynchronous ke daftar file. AIO-Stress adalah utilitas dasar untuk menguji api AIO kernel Linux.. Bagian bar kedua mewakili tes Compilebench yang mensimulasikan beberapa IO disk yang umum dalam membuat, mengompilasi, menambal, menyatakan, dan membaca kernel tree. Baik AIO-Stress dan Compilebench dengan skor yang lebih tinggi memiliki performa yang lebih baik. Seperti yang ditunjukkan pada Gambar 7, umumnya Xen Server memiliki kinerja yang lebih baik daripada tiga lainnya meskipun hanya sedikit berbeda kinerja.

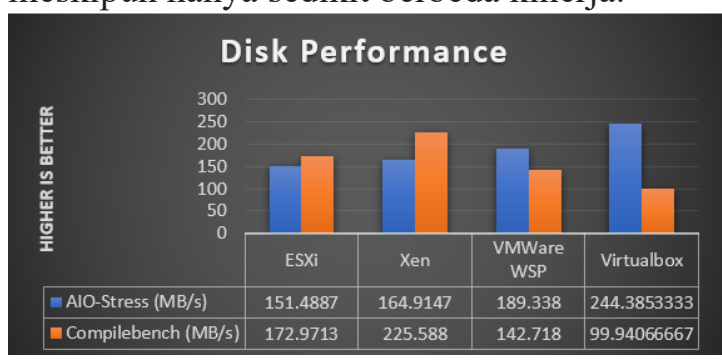

Gambar 6. Kinerja Storage

\section{KESIMPULAN DAN SARAN \\ a. Kesimpulan}

Makalah ini menjelaskan perbandingan kinerja empat hypervisor, ESXi, Xen Server, VMware Workstation Pro dan Virtualbox dengan benchmark phoronix test suite. Penulis menguji tiga komponen yaitu CPU dengan uji Cachebench Read dan Cachebench Write , RAM dengan Ramspeed Floating Point, Stream dan Tinymembench serta Disk dengan AIO-Stress dan Compilebench. Hasil benchmarking, dengan sumber daya yang sama kinerja CPU server Xen sedikit lebih baik dari ketiga lainnya. Kinerja RAM, Xen juga lebih baik dari ketiga hypervisor lain. Dan kinerja storage, Xen juga lebih baik dari ketiga hypervisor lainya.

\section{b. Saran}

Dari proses penelitian ini, penulis dapat memberikan beberapa saran untuk penelitian selanjutnya terkait dengan performa hypervisor.

Peneliti dapat mencoba menggunakan lebih banyak instrumen penguji untuk setiap objek pengujian hypervisor, contohnya untuk pengujian ditambah menggunakan instrumen linux-kernel-compilation, byte, blogbench atau yang lainya.

Obyek pengujian bisa ditambahkan dengan pengujian kinerja jaringan dengan menjaga koneksi jaringan stabil (jaringan lokal tanpa ada intervensi).

\section{REFERENSI}

Cramer, D. (1998). Fundamental Statistics for Social Research. Routledge.

Fayyad, H., Perneel, L., \& Timmerman, M. (2013). Benchmarking the Performance of Microsoft Hyper-V server, VMware ESXi and Xen Hypervisors. Journal of Emerging Trends in Computing and Information Sciences, 4(12), 922-933.

Finn, A., \& Lownds, P. (2011). Mastering Hyper-V Deployment. SYBEX Inc.

Graniszewski, W., \& Arciszewski, A. (2016). Performance analysis of selected hypervisors (Virtual Machine Monitors VMMs). International Journal of Electronics and Telecommunications, 62(3), 231-236. https://doi.org/10.1515/eletel-2016-0031

Green, J., Lowe, S. D., \& Davis, D. M. (2018). The Fundamentals of Hyperconverged Infrastructure. 48. www.actualtechmedia.com

Hwang, J., Zeng, S., \& Wood, T. (2014). A component-based performance comparison of four hypervisors. Integrated Network Management ..., May 2014, 269-276. http://ieeexplore.ieee.org/xpls/abs_all.jsp ?arnumber $=6572995$

Karande, S., \& Dhargave, S. (2015). Evaluation of different Hypervisors Performances using Different Benchmarks. January 2015.

Manik, V. K., \& ARORA, D. (2016). Performance Comparison of Commercial VMM : 1771-1775.

Mulyana, E. (2015). BUKU Komunitas SDNRG. GitBook. https://doi.org/10.1002/ejoc.201200111

Poojara, S. R., Dharwadkar, N. V., \& Ghule, V. (2018). Performance benchmarking of hypervisors- A Case Study. Indian Journal of Science and Technology, 10(44), 1-11. https://doi.org/10.17485/ijst/2017/v10i4 4/120579 